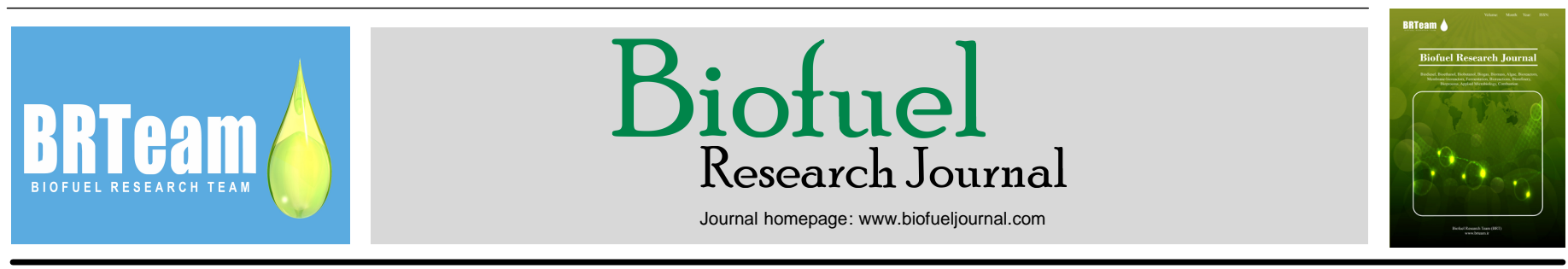

Original Research Paper

\title{
Growth and characterization of deposits in the combustion chamber of a diesel engine fueled with B50 and Indonesian biodiesel fuel (IBF)
}

M Taufiq Suryantoro*, Bambang Sugiarto, Fariz Mulyadi

Departement of Mechanical Engineering, University of Indonesia, 16424 Depok West Java, Indonesia.

\section{HIGHLIGHTS}

$>$ Deposits formation as one of the main challenges

for biodiesel utilization was investigated.

$>$ Deposits structure and compositions were

compared and found to be different for Indonesian

biodiesel fuel (IBF) and B50.

$>$ Higher inclusion rate of biodiesel increased

deposits formation on engine components, especially

on the valves and injector tip.

\section{GRAPHICAL ABSTRACT}

\section{ARTICLE INFO}

Article history:

Received 13 April 2016

Received in revised form 9 August 2016

Accepted 16 August 2016

Available online 1 December 2016

\section{Keywords:}

Biodiesel

Indonesian biodiesel fuel (IBF)

Endurance test

Deposit growth

Deposit composition

Deposits structure

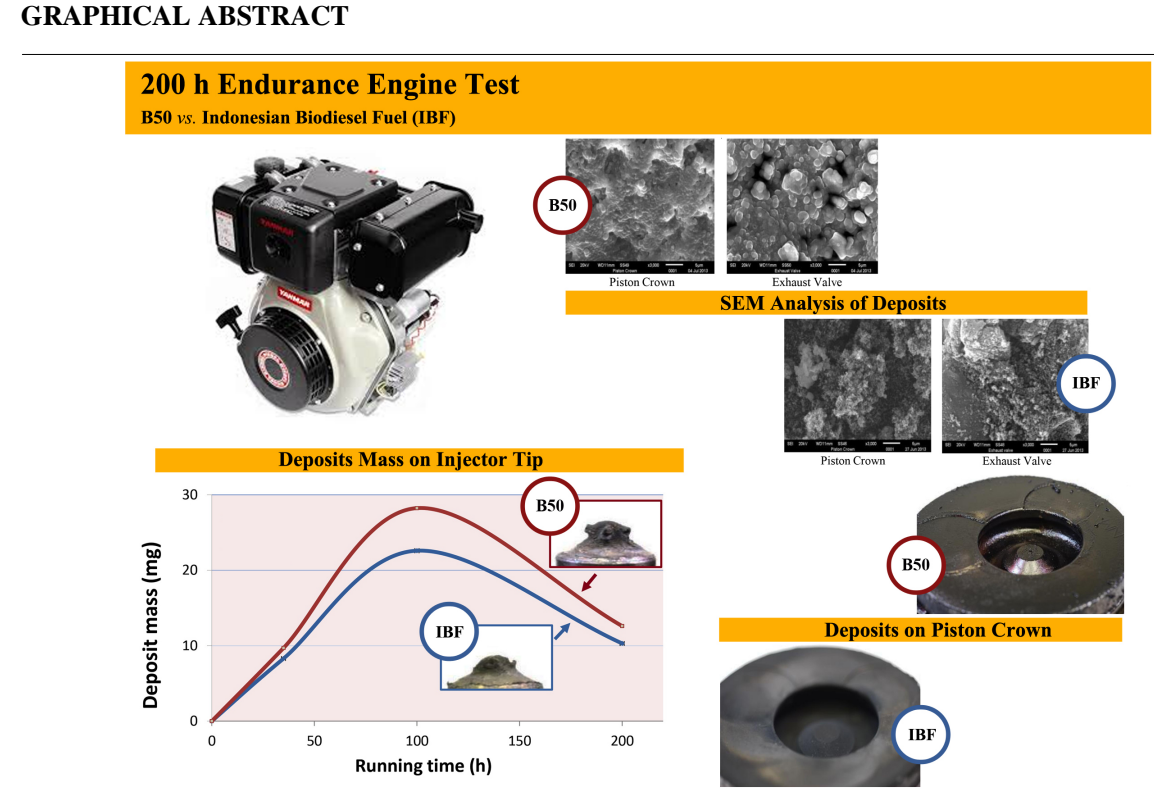

\begin{abstract}
Although used since 1893, biodiesel still faces problems that must be overcome before it can fully replace petroleum diesel. Existing literature shows that continuous use of biodiesel could lead to higher growth of deposits on critical engine components, contributing to lots of problems that could ultimately decrease engine performance. In this context, endurance tests were performed to compare the impacts of B50 and Indonesian biodiesel fuel (IBF: diesel fuel containing $10 \%$ palm oil biodiesel) on engine durability. More specifically, deposits growth as well as deposits structure and composition in response to the application of the above-mentioned fuel blends were investigated over $200 \mathrm{~h}$. The results revealed that B50 produced relatively larger amounts of deposits especially on the valves and injector tip while also increased the risk of ring sticking. In addition, the structure and the elemental composition of the deposits formed on engine important components, i.e., injector tips, piston crown, intake/exhaust valves, cylinder head, and piston grooves when B50 was used were quite different compared with the IBF. Overall, more deposits formation was observed by increasing biodiesel inclusion rate especially on the valves and injector tip, while deposits tended to be wet and brittle as well.
\end{abstract}

(C) 2016 BRTeam. All rights reserved.

* Corresponding author at: Tel.: +62 217560539

E-mail address: taufiq_suryo@yahoo.co.id

Please cite this article as: Suryantoro M.T., Sugiarto B., Mulyadi F. Growth and characterization of deposits in the combustion chamber of a diesel engine fueled with B50 and Indonesian biodiesel fuel (IBF). Biofuel Research Journal 12 (2016) 521-527. DOI: 10.18331/BRJ2016.3.4.6 


\section{Introduction}

Owing to the growing industrialization and the expanding transportation sector around the globe, demands have largely increased for various fossiloriented energy carriers. However, the limited amount and the uneven distribution of these nonrenewable energy resources have led to a worldwide search for renewable or alternative energy resources. To achieve economic viability, it is important to try to develop renewable energies whose feedstocks are available and locally-abundant. Indonesia and the other tropical countries have focused on the production of renewable energies such as biodiesel or bioethanol using both edible and non-edible plants such as palm, coconut, Jatropa curcas, Calophyllum inophyllum, rubber seed, Schleicheera oleosa, etc.

In the year 2016, Indonesia committed itself to increase the use of biodiesel from 10 to $20 \%$ (http://www.migas.esdm.go.id/) through the implementation of a program called "Peraturan Menteri EDM No. 12 Tahun 2015". Accordingly, Indonesian should use Fatty Acid Methyl Esters (FAMEs) produced from palm oil to substitute petroleum diesel fuel while the replacement rate is supposed to be increased slightly every year in order to reduce diesel fuel imports. Nevertheless, such implementation is not without any problems either. One of the most crucial problems associated with the growing application of biodiesel is the excessive formation of carbon deposits in the combustion chamber. This is ascribed to the fact that biodiesel blends have less thermal stability as well as higher density and viscosity values compared with typical diesel fuel, thus increasing the possibility of deposit formation in engines (Reksowardojo et al., 2010; Liaquat et al., 2014). These deposits could negatively impact heat transfer in the combustion chamber (Yamada et al., 2002; Kalam and Masjuki, 2004), hydrocarbon emissions (Caceres et al., 2003; Gopal and Karupparaj, 2015), and the overall quality of the combustion process and the components' lifetime which could ultimately result in increased maintenance cost. It is worth highlighting that various biodiesel blends vary in terms of their physicochemical properties and consequently their combustion characteristics.

Therefore, researchers in various countries have been conducting experiments in order to scrutinize the use of biodiesel both at laboratory and industrial scales. Agarwal (2007) in a review paper concluded that based on the long-term endurance tests, biodiesel can be used as a substitute for mineral diesel. In spite of such efforts, the usability of biodiesel and its blends especially in accordance with engine durability is still in question. There are various editions of the European (EN) and American (ASTM) standards for different biodiesel inclusion rates in petroleum diesel. For instance, EN 590:2004 and ASTM D975 allow only 5\% biodiesel to be blended into diesel fuel. In general, most car manufacturers recommend maximum biodiesel inclusion rate of only $5 \%$ in order to avoid undesirable impacts on unmodified engines such as deposits formation (Joint FIE Manufacturers Statement, 2009).

To address this challenge, further studies and comprehensive research activities with a focus on fuels' characteristics and their deposit formation capability in different engine parts are strongly required. It is worth quoting that research on deposit formation in injector and combustion chamber basically includes measuring the thickness of the deposits in the engine componentd in response to the application of test and reference fuels. Deposits can contain various materials and residues which gradually grow or accumulate on critical parts of internal combustion engines (Güralp et al., 2006; Arifin and Arai, 2009). Therefore, it is essential to analyze the chemical and physical attributes of deposits in order to figure out the causes. Deposit characterization generally includes structural and compositional analyses through scanning electron microscopy (SEM) and Energy Dispersive Spectroscopy (EDS). Having considered both diesel fuel and biodiesel as references, the deposits formed can be compared for different fuel compositions.

The objective of the present study was to investigate the formation of deposits in the combustion chamber of a diesel engine and to characterize them when Indonesian biodiesel fuel (IBF) containing 10\% palm oil biodiesel and B50 fuel were used. The investigated parameters included the rate of deposit growth on several diesel engine components, the composition of the deposits, the morphological features of the deposits formed on different engine componentd, and how the rate of deposit growth affected engine's performance.

\section{Materials and Methods}

\subsection{Experimental set-up and deposit analysis procedure}

Descriptive results on deposit growth in different parts of a diesel engine were obtained by conducting $200 \mathrm{~h}$ endurance tests for each of the investigated fuel blends. Deposits are more likely be formed when engines reach maximum power or maximaum torque at low combustion chamber temperature, combined with engine cooling. Therefore, the present study was conducted mostly at maximum torque.

As mentioned earlier, the duration of the endurance test was $200 \mathrm{~h}$ After 35,100 , and $200 \mathrm{~h}$ of the test, the engine was dismantled in order to analyze deposit growth by photography and mass weighing in different engine components, i.e., piston crown, piston grooves, cylinder head, injector tip, intake valve, and exhaust valve. A digital single lens camera was used to capture the images. Since the deposits were formed in micro scale thickness, and as a result of the complexity of the engine components, it was difficult to get deposit thickness for every engine component and, therefore, non-destructive method (photographic method) was used. The images obtained were further processed by using a photo editing software and MATLAB program (MATLAB, 2013) to obtain coordinate points, visualizing the injector in the form of graphs, and to estimate the deposits volume through the integration process (Table 1).

Table 1.

The deposit mass calculation approach

\begin{tabular}{ccc}
\hline $\begin{array}{c}\text { Taking images at } 4 \\
\text { different angles }\end{array}$ & Processing images & $\begin{array}{c}\text { Production of output 3-D } \\
\text { images }\end{array}$ \\
\hline & &
\end{tabular}

Engine off mode was used to stimulate cooling condition as used in real field. Moreover, the structure and chemical composition of the deposits were also analyzed by using a JEOL JSM-6510 LA SEM-EDS (3000× magnification). Smoke samples from the smoke filter were also taken and analyzed in order to investigate their relation with the deposits formed in the valves.

A single cylinder Yanmar L48 diesel engine (Table 2) was used in the experiments. A single-phase Dongdong generator with a $3.5 \mathrm{~kW}$ capacity set with bulbs installed in series was used to gain a constant power of 1.7 $\mathrm{kW}$ (75\% of the engine maximum load capacity) during the $200 \mathrm{~h}$ endurance test. Oil and exhaust temperatures were recorded every $2 \mathrm{~h}$, while smoke and fuel flow rates were logged in every $4 \mathrm{~h}$.

Table 2.

The specifications of the engine set-up used.

\begin{tabular}{lll} 
Engine Model & L48N \\
\hline & $\begin{array}{l}\text { Type } \\
\text { air cooled diesel engine, } \\
\text { direct injection }\end{array}$ \\
\cline { 2 - 3 }
\end{tabular}




\section{Results and Discussion}

Deposits or as they are often called carbon deposits in the combustion chamber of diesel engines are heterogenic mixtures consisting of carbon ash, soot, and the residues of oxygenated materials. In a comprehensive study, Diabya et al. (2009) argued that down-sizing of the engine as well as extreme conditions of the engine operation, e.g., operational temperature and pressure of the combustion chamber, oil sump, or cylinder liner temperature could accelerate the deposits formation process in engines. These deposits remain attached to the critical parts of the combustion chamber such as piston (crown, rings, and crevices), cylinder head, intake and exhaust valves and injector. Deposits on the injector often occur on the injector tip and in the interior of the fuel oulet. It is worth quoting that deposits gradually grow and accumulate in these critical parts and will negatively affect engine durability and consequently the maintenance cost.

Besides, deposits accumulation on the wall of the combustion chamber could interfere with heat transfer in the combustion chamber leading to increased $\mathrm{NO}_{\mathrm{x}}$ emission ( $\mathrm{Ra}$ et al., 2006). It has been reported that the thickness of deposits could be estimated by measuring the temperature of the combustion chamber wall and the area of fuel impingement (Goldsworthy, 2006; Güralp et al., 2006). The combination of low wall temperature and unburned fuel could cause more deposit formation in the engine chamber. Overall, deposit formation in the combustion chamber is a complex process that depends on several interrelated parameters, i.e., fuel type, the material used in the combustion chamber wall, temperature, compression, etc. Among those, the wall is the most important parameter in the formation of deposits (Arifin and Arai, 2009).

Spilners and Hedenburg (1985), who studied carbon deposit formation in a single cylinder test engine, observed that the olefin content of the fuel had the greatest effect on the deposit formation tendency. Fuel injectors in

diesel engines are precision instruments and their function is to control engine combustion, fuel economy, and engine noise by injecting exactly the right amount of fuel into the combustion chamber on each compression stroke. Carbon deposits formed on the jnjector may cause operational problems, such as excessive smoke emissions, loss of power, poor fuel economy, degraded emissions, excessive engine noise, rough engine operation, and poor drivability. It is worth quoting that the jnjector carbon deposits, usually appearing as lacquers on the piston, are believed to result from the reactions of the oxidation products of unstable fuel blends, e.g., when high biodiesel inclusion rates are practiced (Goldsworthy, 2006).

\subsection{Deposit growth}

Deposits in the combustion chamber of a diesel engine are classified based on their location into 5 categories: injector tips, piston crown, intake/exhaust valves, cylinder head and piston grooves. Deposit growth was measured by gravimetric and photographic methods. Extent of deposit growth on the injector tips can be seen in Figure 1. More specifically, Figure 1A shows deposit growth on the injector tip by time in the engine running on the IBF fuel blend, while Figure 1B presents the trend of deposit growth when the B50 fuel was utilized. Visual inspection of the injector nozzles at the end of each running test for various fuel blends i.e., diesel containing coconut oil, was also conducted previously by Kalam et al. (2003) who indicated that there was no significant carbon deposit on the nozzle tips. In a different study on analyzing the wear of various vital engine parts, Agarwal et al. (2003) reported up to $30 \%$ wear reduction in response to additional lubricity properties of linseed biodiesel added to the fuel (B20). Similar observations made in the present study, i.e., wear reduction using both B50 and IBF (Fig. 1). From the data presented in Figure 1A, it could be concluded that the IBF fuel led to a more efficient combustion during the test. Moreover, an increase in deposit mass after $100 \mathrm{~h}$ of the endurance test was observed but it was slightly decreased by the end of experiment, i.e., after $200 \mathrm{~h}$. Physically, the deposits were found harder and drier, but more brittle compared with the deposits found on the cylinder head or piston crown. As a result, they could be easily shed off from the injector tip surface.

Deposit growth in the engine fueled by B50 showed a different trend (Fig. 1B) as after the first $35 \mathrm{~h}$, the thickness of the deposits increased sharply. Moreover, the deposits were relatively soft and wet/oily. The wet nature of the deposits is ascribed to the presence of lots of fuel residues and therefore, these deposits are flammable.

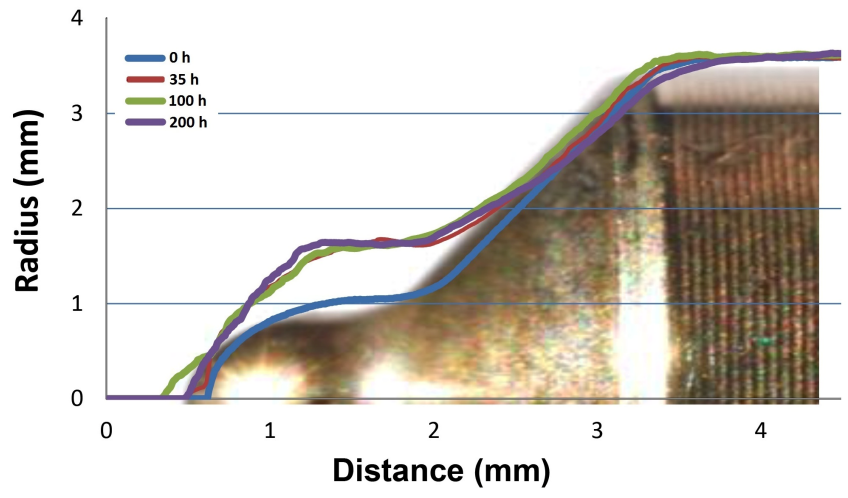

B

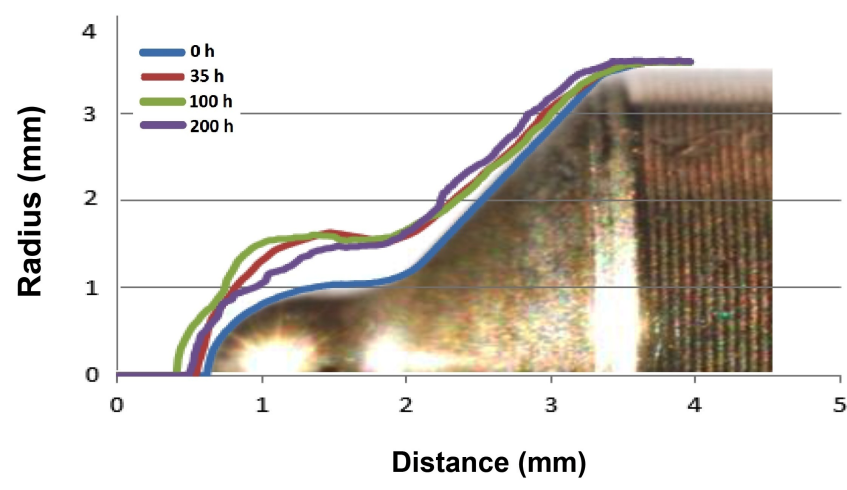

Fig.1. Deposit growth on the injector tip in the engines running on, A) IBF and B) B50.

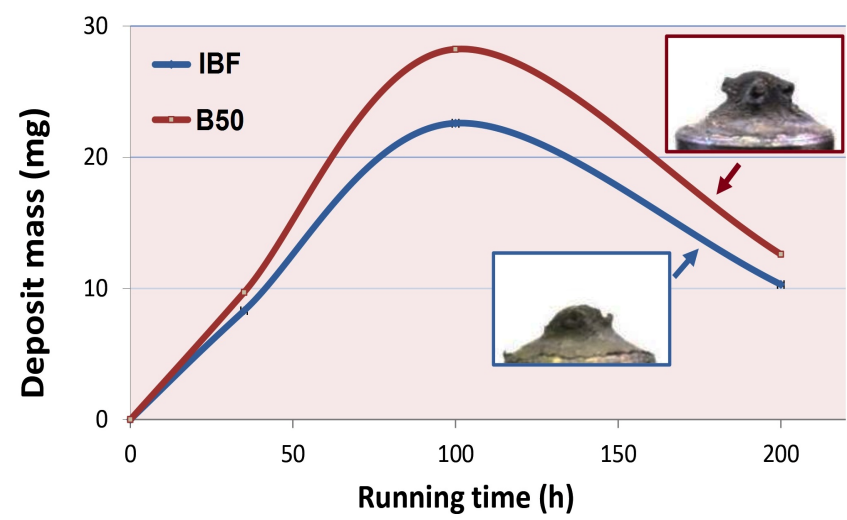

Fig.2. Deposit growth on the injector tip using IBF and B50 after $100 \mathrm{~h}$ of engine operation.

Figure 2 also shows the deposit mass generated on the injector tip. As presented B50 led to higher deposit mass than IBF. Furthermore, the deposits were found wetter, thicker and more brittle in the hole of the nozzle. In general, deposit growth in the engine running on B50 was considerably higher than in the engine running on IBF. These results were in agreement with those of Reksowardojo et al. (2010) and Liaquat et al (2014). Table 3 tabulates the data obtained on deposit volume and mass on the injector tip using IBF and B50. As shown, after $100 \mathrm{~h}$, a decrease in deposit volume occurred using both fuel types. Measurements were 
conducted by using both photography and mass weighing in order to minimize errors. For instance, weighing has its own shortcoming of taking the true mass stuck in an engine part into account owing to the presence of nondeposit mass, i.e., oil and fuel residues.

Table 3.

Deposit volume and mass in injector tip uses IBF and B50.

\begin{tabular}{ccccc}
\hline $\begin{array}{c}\text { Endurance } \\
\text { test }(\mathbf{h})\end{array}$ & $\begin{array}{c}\text { Deposit vol. } \\
\text { using IBF } \\
\left(\mathbf{m m}^{\mathbf{3}}\right)\end{array}$ & $\begin{array}{c}\text { Deposit vol. } \\
\mathbf{B 5 0} \\
\left(\mathbf{m m}^{\mathbf{3}}\right)\end{array}$ & $\begin{array}{c}\text { Deposit mass } \\
\text { using IBF } \\
(\mathbf{m g})\end{array}$ & $\begin{array}{c}\text { Deposit mass } \\
\text { using B50 } \\
(\mathbf{m g})\end{array}$ \\
\hline 35 & 44.586 & 45.201 & 8,30 & 9.70 \\
100 & 50.884 & 53.371 & 22,59 & 28,23 \\
200 & 45.463 & 46.497 & 10.30 & 12,60 \\
\hline
\end{tabular}

The trend observed in deposits formation by time in the intake and exhaust valves are shown in Figure 3A and B, respectively. As presented, the deposit mass measured in the intake valve using B50 was higher than that of IBF.
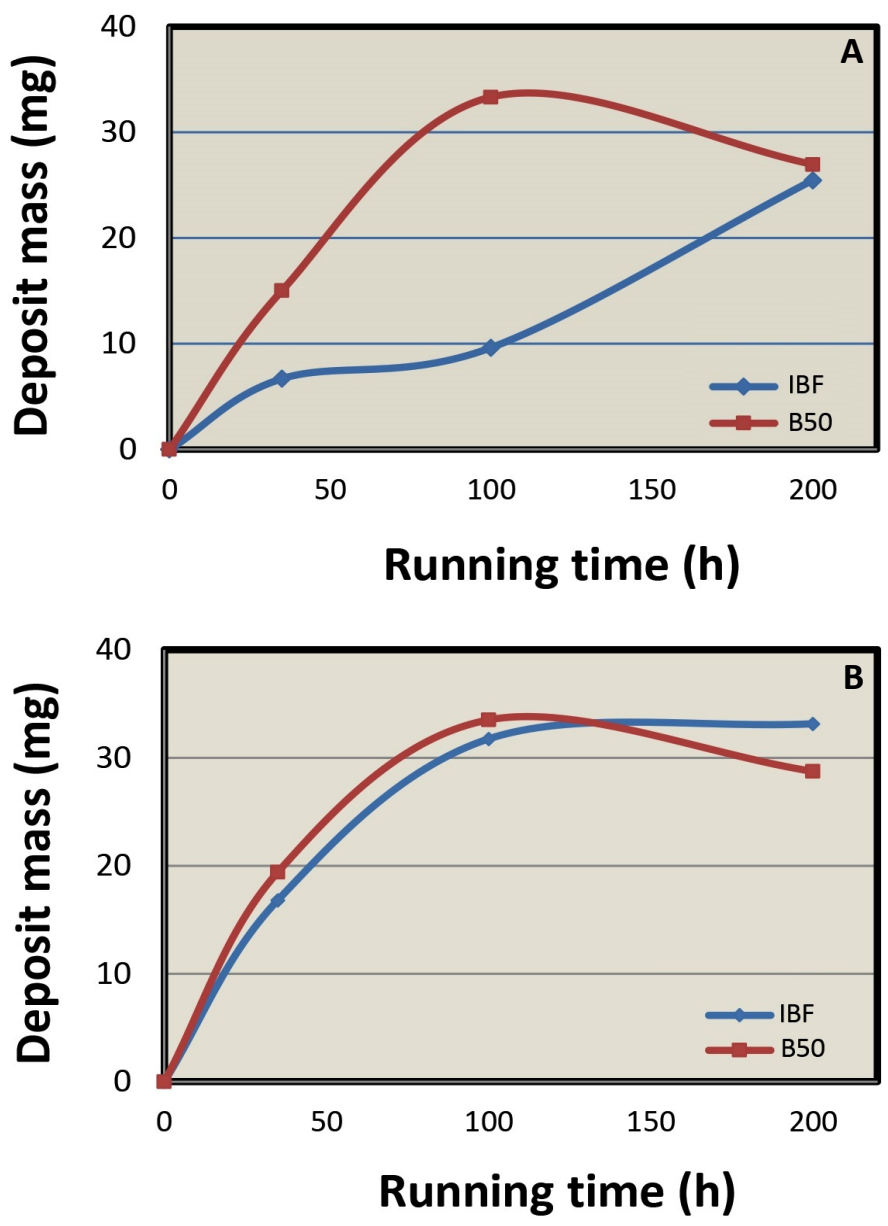

Fig.3. Deposit mass growth trends on, A) the intake valve and B) the exhaust valve using IBF and B50.

This could be attributed to the swelling of rubbers as a result of high biodiesel inclusion as in B50 and the consequent oil leakage to the combustion chamber. Rubber swelling did not happen when IBF was used during $200 \mathrm{~h}$ of endurance test while the application of B50 resulted in the swelling of the intake valve rubber after only $100 \mathrm{~h}$ of operation (Fig. 4). As for the exhaust valve, the mass of deposits formed were relatively similar using both fuels after $200 \mathrm{~h}$ of engine operation. Moreover, the deposits formed in the exhaust valve using both fuels were brittle and could be easily detached from the valve surface. In a study, Ziejewski et al. (1984) formulated, characterized, and evaluated a nonionic sunflower oil-aqueous ethanol microemulsion as fuel in a diesel engine during a 200 $\mathrm{h}$ endurance test. After each durability test, the carbon, sludge and varnish deposits were rated to directly measure the wear of the engine components. Contrary with the findings of the present study, no differences in deposits formation in the intake and exhaust valves were detected for the tested fuels. More specifically, in their study, all valve seats as well as all valve faces showed light peening caused by hard particles released from the combustion chamber deposits while light carbon residue and amber lacquer were noted on the intake valve faces and on the valve stems, respectively.

It is worth mentioning that deposit growth in the other engine components such as cylinder head, piston crown, and piston ring could not be quantified herein by using the photography method while the deposits growth on the cylinder head and piston ring could be measured by the weighing method through shedding off all the deposits stuck on the component's wall. None of the methods were capable of measuring the mass of deposits stuck in the piston ring accurately. Simillar studies were conducted by Ziejewski et al. (1983 and 1984) in which all pistons

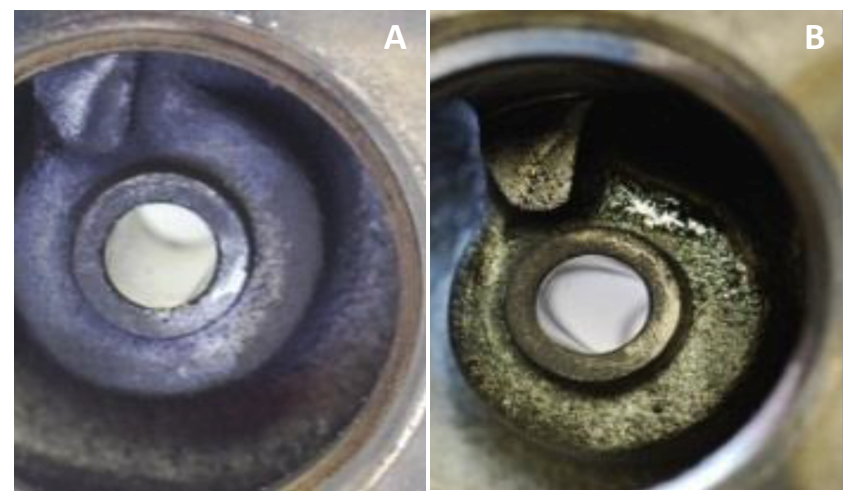

Fig.4. Intake valve seat condition using, A) IBF and B) B50 after $100 \mathrm{~h}$ of engine operation.

showed significantly greater carbon and lacquer buildups in the ring grooves and on the piston lands, as well as on the piston undercrowns and skirts. Moreover, in a comparative study, Agarwal et al. (2011) in a qualitative analysis of soot formation on engine components under EGR operation condition found that higher soot deposits were formed on the cylinder head, injector tip, and piston crown when EGR was used compared with the condition where the engine was operated without EGR More specifically, the wear of top compression ring in the engine operated with EGR was found to be slightly lower than the engine operated without EGR that may be due to the lower combustion temperature. But the wear of the second and third compression rings as well as the oil ring in the engine operated with EGR was far more than those of the engine operated without EGR.

\subsection{Deposit structure}

The deposits formed in different components, i.e., piston, valve, cylinder head, and injector were quite different in structure (Fig. 5). As presented, the deposits particles formed as a result of B50 were bigger in comparison with IBF (Fig. 5). Moreover, the shapes of the deposits 


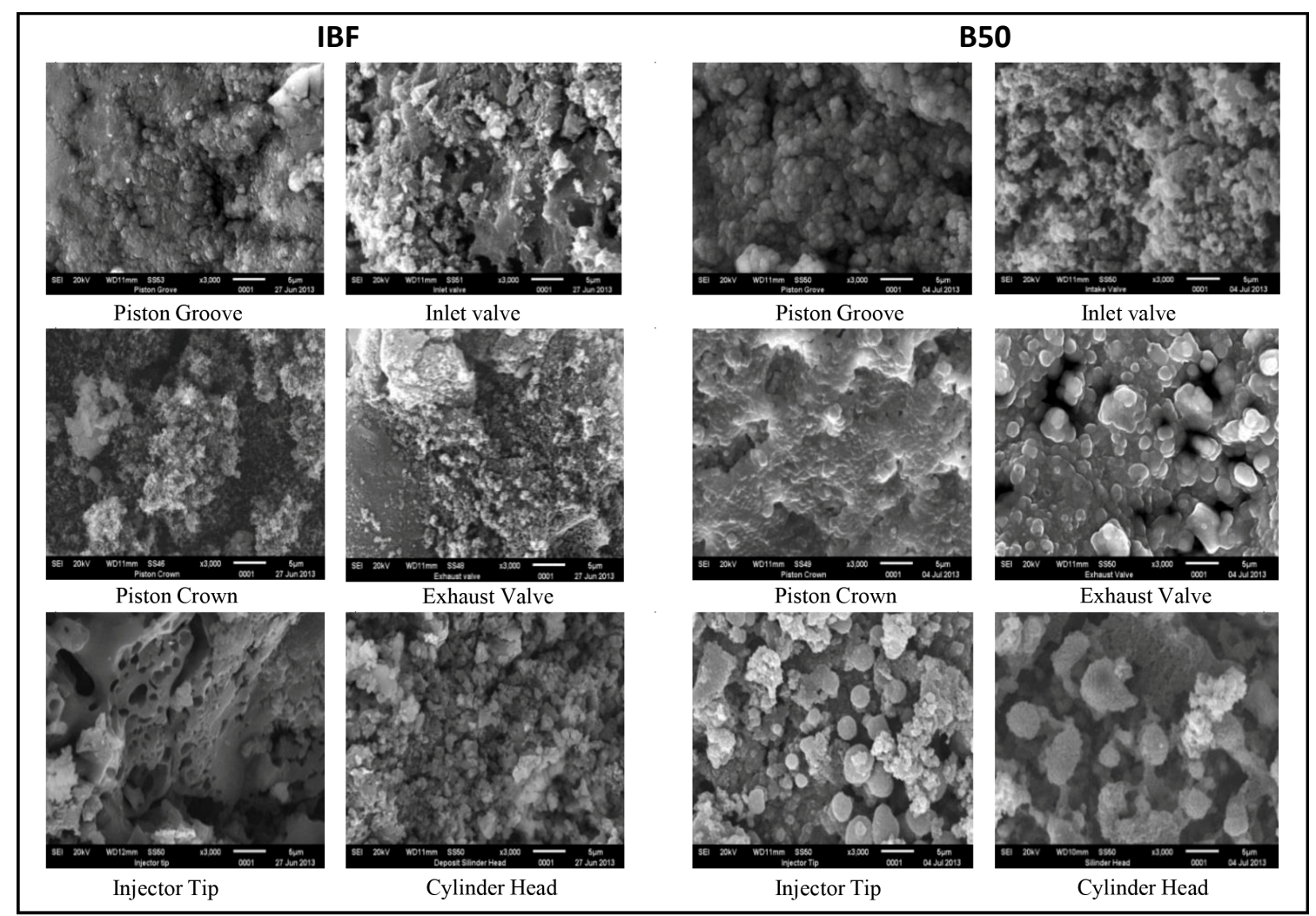

Fig.5. SEM monographs showing deposit structure on different engine components (3000×).

obtained were also different. More specifically, the deposits particles formed in the B50-fueled engine had a relatively soft shape, while in the IBF-fueled engine deposits were sharp. This could be attributed to the wetness of the deposits and the fact that were not evaporated completely. The spherical structure of the deposits in the B50-fueled engine was likely ascribed to the presence of long chain hydrocarbons and unstable compounds in the fuel. Long chain hydrocarbons cause the fuel harder to evaporate, whereas unstable compounds in fuel lead to fuel oxidization and the formation of polymers. The formation of deposit in the piston groove was not impacted by fuel type and the changes observed were not significant. Similarly, deposit structures in intake valve using IBF and B50 were also not significantly different.

Figure 6 revealed that after $200 \mathrm{~h}$ of the endurance test, the piston surface was significantly different using the investigated fuels. More specifically, IBF-derived deposits were relatively dry while B50-derived deposits were wet/oily. This may be caused by the unburned fuel articles which failed to diffusely combust after being sprayed by the injector, possibly because of insufficient air fuel ratio (AFR). It has been mentioned that the deposits caused by unburned fuel, and thus wetter than the other deposits on the wall, were thicker (Arifin and Arai, 2009). This was also observed in the present study on the piston crown and especially on the injector tip.

\subsection{Deposit composition}

Besides morphological variations in the deposits formed, elemental composition of the deposits in different engine components were also analyzed herein. As mentioned earlier, deposits are a layer of various materials and residues gradually grown or accumulated on critical parts of internal combustion engines. More specifically, deposits are a pile of soot and solid particles that stick on a thin liquid layer in the combustion chamber and is compressed by the high compression present in the combustion chamber. The theory of deposits formation was formulated by Lepperhoff and Houben (1993) and was further developed in the present study by identifying the

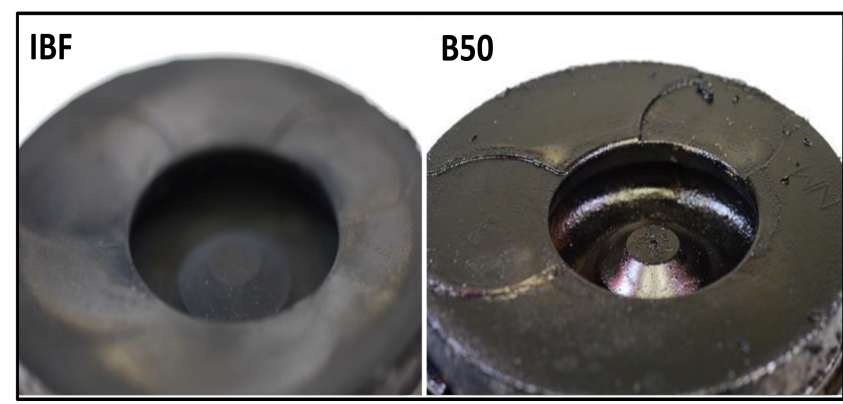

Fig.6. Piston crown condition after dismantling the engines running on IBF (dry) and B50 (wet).

elements found in the deposits. The results obtained by EDS revealed that the deposits in the piston crown of the B50-fueled engine contained a high level of calcium (Fig. 7). This element can also be found in oil lubricants as detergent or corrosion inhibitors. While in the IBF-fueled engine, calcium content was considerably lower. In addition to calcium, zinc was also found in the deposits. Zinc is known as additive for anti-wear and oxidant in most oil lubricants (Nicholls et al., 2005). Elemental comparison also showed that $\mathrm{O} / \mathrm{C}$ content of the deposits formed on the injector tip was higher when IBF was used compared with B50. These findings were similar to those of Liaquat et al. (2014) who also argued that although B50 fuel contained more oxygen but the resultant deposits contained less oxygen. This could probably indicate that the deposits formed on the B50-fueled engine were easier to be oxidized or burned. 
A
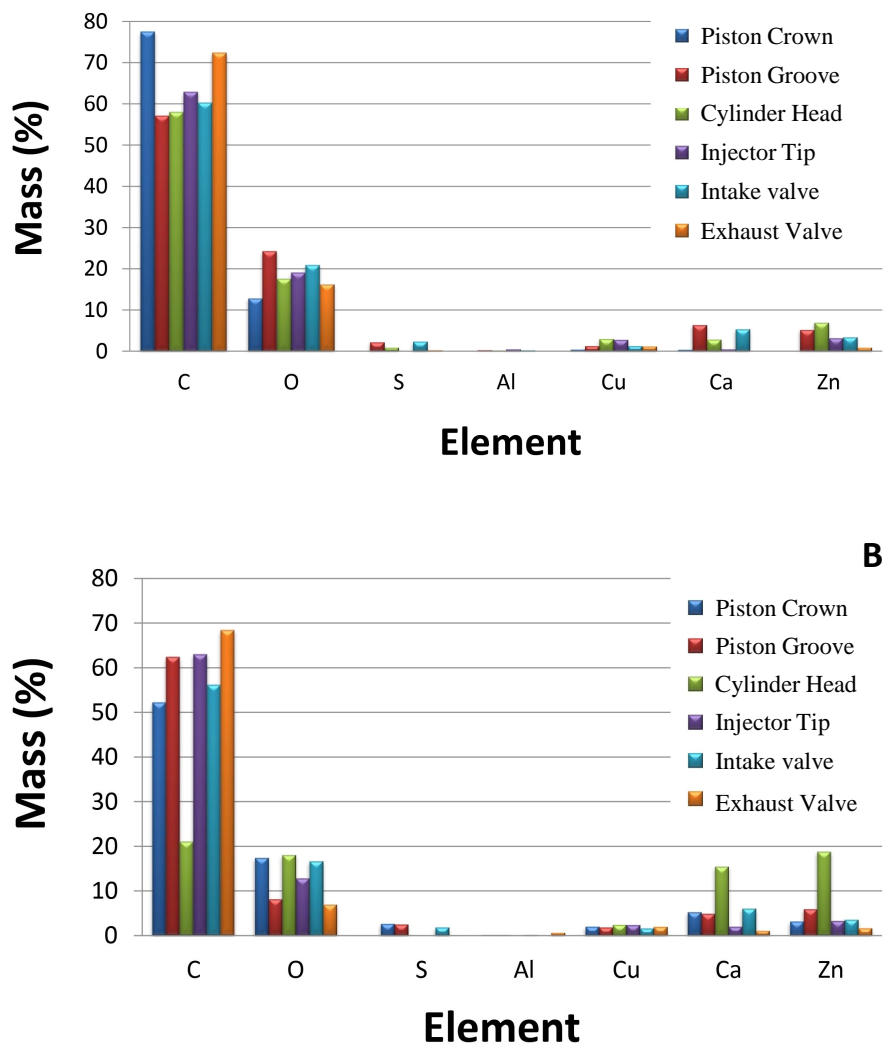

Fig.7. Elemental composition of the deposits formed on different engine components using, A) B50 and B) IBF.

As for the deposits stuck in the piston groove of both IBF and B50 fueled engines, calcium and zinc were found indicating that the piston groove was loaded with lubricant, i.e., biodiesel. In general, the zinc found in wear debris could be because of additive depletion, extra additives being added due to addition of make-up oil, wear of bearings, brass components, neoprene seals, etc. (Agarwal et al., 2003). An important observation was made by Agarwal et al. (2003) who claimed that the application of B20 led to approximately $65 \%$ less increase in zinc content indicating less wear of zinc-containing components and lower consumption of the lubricating oil in comparison with neat diesel fuel.

Overall, the deposits morphology and elemental composition in the piston groove were similar using both fuel blends, i.e., B50 and IBF (Figs. 5 and 7). Traces of potassium and calcium were also identified in the deposits proving that lubricant oil was present in the deposits. In the intake and exhaust valves, the percentage of carbon mass and oxygen deposited in IBF-fueled engine was higher than in B50-fueled engine. Moreover, in the intake valve, the deposits found contained $\mathrm{Fe}, \mathrm{Mg}$, and $\mathrm{Mo}$, which are the elements of the wear debris (Liaquat et al., 2014). On the whole, the elemental compositions obtained in the present study revealed lubricant leakage caused by B50 as a result of rubber swelling. Moreover, the deposits in the exhaust value when B50 was used contained a trace of aluminum indicating the occurrence of metal wear process in the piston ring as a sign of ring sticking. The copper measured in the wear debris basically originates from wear of bearings, and bushings (Fig. 7). Agarwal et al. (2003) also argued that the lubricating impacts of B20 resulted in approximately $25 \%$ lower copper content revealing less wear when compared with neat diesel fuel.
The formation processes of carbonaceous deposits in the first piston ring grooves of direct injection diesel engines were studied by Diaby et al. (2009). Their analyses showed that the deposits, with a structure of cracked varnishes, mainly resulted from the degradation of lubricants. These deposits contained a noticeable proportion of metallic elements resulting from the wear of metallic parts of the engine. According to their results, the degradative oxidation of the lubricant apparently induced polymerization reactions which in turn led to the formation of a varnish acting as a binder. The formed binder bridged between carbon particles and metallic particles of wear and worsened the cycle of lubricant degradation (Diaby et al., 2009).

\section{Conclusions}

Based on the findings of the present study, the following conclusions can be drawn:

- The higher inclusion rate of biodiesel increased deposits formation on engine components, especially on the valves and injector tip.

- By increasing biodiesel inclusion rate, a tendency toward increased ring sticking was observed.

- B50 fuel led to a large amount of deposits. More specifically, the use of B50 showed excessive wetness in the piston crown. This could be ascribed to the fact that the injected fuel hitting on the piston crown wall would fail to dry, thus making the B50-caused deposits tend to be wet and brittle.

- Based on the deposits morphology, in every engine component, different shapes could be observed even by using the same fuel. By using different fuels, different deposit structures were detected in similar parts of the engine, especially in the injector tip, piston crown, and cylinder head. This was not observed in the exhaust valve and ring groove.

- In the B50-caused deposits, spherical patterns dominated the structures observed. This could be mainly attributed to the unburned fuel that failed to properly combust, and would later dominate the deposits structure. This deposit structure is similar to deposit structure observed in the piston groove.

\section{Acknowledgements}

The authors would like to especially thank BTMP-BBPT for their utmost support by providing facilities and funds. We also would like to extend our appreciation to BATAN who helped with Tomography and SEM analyses.

\section{References}

[1] Adams, C., Peters, J.F., Rand, M.C., Schroer, B.J., Ziemke, M.C. 1983. Investigation of soybean oil as a diesel fuel extender: endurance tests. JAOCS. 60(8), 1574-1579.

[2] Agarwal, A.K., Bijwe, J., Das, L. M., 2003. Effect of biodiese utilization of wear of vital parts in compression ignition engine J. Eng. Gas Turb. Power. 125, 604-611.

[3] Agarwal, A.K., 2007. Biofuels (alcohols and biodiesel) applications as fuels for internal combustion engines. Prog. Energy Combust. Sci. 33, 233-271.

[4] Agarwal, D., Singh, S.K., Agarwal, A.K., 2011. Effect of Exhaust Gas Recirculation (EGR) on performance, emissions, deposits and durability of a constant speed compression ignition engine. Appl. Energ. 88, 2900-2907.

[5] Arifin, Y.M., Arai, M., 2009. Deposition characteristics of diesel and bio-diesel fuels. Fuel 88(11), 2163-2170.

[6] Caceres, D., Reisel, J.R., Sklyarov, A., Poehlman, A., 2003. Exhaust emission deterioration and combustion chamber deposits composition over the life cycle of small utility engine. J. Eng. Gas Turbines Power. 125(1), 358-364.

[7] Diabya, M., Sablier, M., Negrateb, A. L., El Fassi, M., Bocquet, J., 2009. Understanding carbonaceous deposit formation resulting from engine oil degradation. Carbon 47, 355-366. 
[8] Goldsworthy, L., 2006. Computational fluid dynamics modeling of residual fuel oil combustion in the context of marine diesel engines. Int. J. Engine Res. 7(2), 181-199.

[9] Gopal, K.N., Karupparaj, R.T., 2015. Effect of pongamia biodiesel on emission and combustion characteristics of DI compression ignition engine, Ain Shams Eng. J. 6(1), 297-305.

[10] Güralp, O., Hoffman, M., Assanis, D.N., Filipi, Z., Kuo, T.W., Najt, P. Rask, R., 2006. Characterizing the effect of combustion chamber deposits on a gasoline HCCI engine. SAE technical paper, No. 2006-013277.

[11] Joint FIE Manufacturers Statement, 2009, Fuel requirements for diesel fuel injection systems.

[12] Kalam, M.A., Husnawan, M., Masjuki, H.H., 2003. Exhaust emission and combustion evaluation of coconut oil-powered indirect injection diesel engine. Renew. Energ. 28, 2405-2415.

[13] Kalam, M.A., Masjuki, H.H., 2004. Emissions and deposits characteristics of a small diesel engine when operated on preheated crude palm oil. Biomass Bioenergy. 27(3), 289-297.

[14] Lepperhoff, G., Houben, M., 1993. Mechanisms of deposit formation in internal combustion engines and heat exchangers. SAE technical paper, No. 931032.

[15] Liaquat, A.M., Masjuki, H.H., Kalama, M.A., Fazal, M.A., Faheem Khan, A., Fayaz, H., Varman, M., 2013. Impact of palm biodiesel blend on injector deposit formation. Appl. Energ. 111, 882-893.

[16] Liaquat, A.M., Masjuki, H.H., Kalam, M.A., Fattah, I.R., 2014. Impact of biodiesel blend on injector deposit formation. Energy. 72, 813-823.
[17] Nicholls, M.A., Do, T., Norton, P.R., Kasrai, M. Bancroft, G.M., 2005. Review of the lubrication of metallic surfaces by zinc dialkyl-dithiophosphates. Tribol. Int. 38(1), 15-39.

[18] Ra, Y., Reitz, R.D., Jarrett, M.W., Shyu, T.P., 2006. Effects of piston crevice flows and lubricant oil vaporization on diesel engine deposits. SAE Technical Paper. No. 2006-01-1149.

[19] Reksowardojo, I.K., Hung, B.N., Sok, R., Kilgour, A.J., Brodjonegoro, T.P., Soerawidjaja, T.H., Mai, P.X., Shudo, T., Arismunandar, W., 2010. The Effect of biodiesel fuel from Rubber seed oil (Hevea Brasiliensis) on a direct injection (DI) diesel engine, The 3rd Regional Conference on New and Renewable Energy, 1314th, October, Penang, Malaysia.

[20] Spilners, I.J., Hedenburg, J.F., 1985. Effect of Fuel and Lubricant Composition on Engine Deposit Formation, in: Ebert, L.B. (Ed.), Chemistry of Engine Combustion Deposits, Plenum Press, pp. 289-302.

[21] Yamada, Y., Emi, M., Ishii, H., Suzuki, Y., Kimura, S., Enomoto Y., 2002. Heat loss to the combustion chamber wall with deposit in D.I. diesel engine: variation of instantaneous heat flux on piston surface with deposit. JSAE Rev. 23(4), 415-421.

[22] Ziejewski, M., Kaufman, K.R., 1983. Laboratory endurance test of a sunflower oil blend in a diesel engine. JAOCS. 60(8), 1567-1573.

[23] Ziejewski, M., Kaufman, K. R., Schwab A.W., Pryde, E.H., 1984 Diesel engine evaluation of a nonionic sunflower oil-aqueous ethanol microemulsion. JAOCS. 61(10), 1620-1626. 